\title{
Parents' Health and Demographic Characteristics Predict Noncompliance with Well-Child Visits
}

\author{
Ishani Jhanjee, MD, Deepti Saxeena, MD, Jaspal Arora, MD, and \\ Dwenda K. Gjerdingen, MD, MS
}

Background: The purpose of this study was to investigate factors related to well-child visit noncompliance in an ethnically diverse family practice clinic population.

Methods: Participants included 146 parents (131 mothers and 15 fathers) of children aged 0 to 24 months who received care at a St. Paul residency clinic. Participants completed telephone surveys that asked about their demographic characteristics, attitudes toward well-child visits, whether the most recent planned well-child visit had been kept, and their own and their child's health characteristics.

Results: All participants thought that well-child visits were important, with immunizations being the highest rated reason for importance. Fourteen percent of parents said they had missed a recent wellchild visit, mostly because they forgot. More than three fourths of parents believed visit reminders were helpful, and the preferred type of reminder was a telephone call. Noncompliance with well-child visits was associated with the parent's depressive symptoms, transportation difficulties, working at a job, having private (vs public) health insurance, and being older (vs younger).

Conclusions: These results suggest that well-child visit compliance might be enhanced by visit reminders and improved access to transportation. The relationship of well-child visit noncompliance to parental depressive symptoms, if verified in other populations, points to a need for greater surveillance of children/families who do not schedule or keep well-child visits. (J Am Board Fam Pract 2004;17: 324-31.)

Children under the age of 18 make up nearly one fifth of all visits to primary care providers. ${ }^{1}$ Of these visits, well-child visits are the most common and are in fact the leading diagnosis among pediatricians and the sixth leading diagnosis for family physicians. ${ }^{1}$ Well-child visits are important to the health of children, as they are the means whereby children's growth is monitored, diseases are diagnosed, vaccines are administered, and education about nutrition, safety, and other important issues is provided. However, appointments for well-child visits are often not made or kept. For example, a recent historic cohort study of over 300,000 children enrolled in Medicaid in California, Georgia, and Michigan found that $29 \%$ to $51 \%$ of the children (depending on race and location) had only 0 to 1 well-child visits during the first 2 years of their lives. $^{2}$

Submitted, revised, 6 June 2004.

From the Department of Family Practice and Community Health, University of Minnesota Medical School, Minneapolis. Address correspondence to Dwenda K. Gjerdingen, MD, 580 Rice St., St. Paul, MN 55103 (e-mail: dgjerdin@umphysicians.umn.edu).

This work was funded by the UCare Foundation.
Previous studies have explored factors associated with patients keeping or not keeping appointments in general practice. For example, a study of 4669 patients (not necessarily children) from an urban family practice residency clinic found the following factors to be associated with appointment keeping: older age, Asian or white race/ethnicity, private or managed care insurance, longer distances to travel to the clinic, and appointments scheduled for the day on which they contacted the clinic. ${ }^{3}$ Factors that have been associated with visit noncompliance include male gender, ${ }^{4}$ divorced/separated or single status, ${ }^{4}$ younger age,${ }^{5}$ lower socioeconomic status, ${ }^{6}$ unemployment, ${ }^{7}$ alcohol or substance abuse, ${ }^{7} \mathrm{pa}$ rental psychiatric disorder, ${ }^{8}$ absence of telephone reminders, ${ }^{9}$ having no health insurance or being insured through medical assistance, ${ }^{5,10}$ and having appointments that might evoke embarrassment or fear (eg, psychiatry or gynecology appointment). ${ }^{4}$ One study found that provision of a taxicab voucher to pregnant, low income women resulted in a $22 \%$ increase in compliance with attending the initial prenatal visit. ${ }^{11}$ Only one of these studies looked specifically at well-child visits and found that children who had medical insurance, compared with 
those who did not, were more likely to receive preventive care services and less likely to have emergency care visits. ${ }^{10}$

Given the lack of information about factors associated with well-child visit compliance-particularly such potentially changeable factors as transportation availability or parents' mental health-we were interested in examining these relationships at our family practice residency clinic. Bethesda Clinic, located near downtown St. Paul, Minnesota, serves a primarily low socioeconomic group of patients from a variety of ethnic groups, including Southeast Asian, African American, and white. Clinic physicians are providers for UCare, a Medicaid-sponsored Health Maintenance Organization that gives free transportation for clinic visits, when members prearrange for such transportation 1 to 2 days before the visit. Given this transportation benefit, as well as the low income status of many patients, a known risk factor for mental disorders, Bethesda Clinic was considered to be an excellent setting for investigating the relationship of transportation and parents' mental health to visit compliance.

The purpose of the study was to identify potentially modifiable factors associated with failure to attend well-child visits, such as parent's depressed mood, employment status, insurance-funded transportation to visits, or child's poor health. Significant findings could confirm our hypothesis that noncompliance with well-child visits can be a marker for more serious problems (eg, parental depression) and may also suggest practical interventions that would improve well-child visit compliance.

\section{Methods \\ Population}

The study population consisted of parents of children 0 to 24 months of age who received well-child care from January to December, 2002, at Bethesda Clinic, a family practice residency clinic located in St. Paul, Minnesota. Parents who kept a recent well-child appointment, and those who did not keep a recent appointment, or who neglected to make an appointment within one month of a designated well-child visit, were recruited to the study. Excluded from the study were parents who refused to participate, did not speak English or Hmong, did not have custody of the identified child, or were currently using another clinic for well-child care. If a child was designated to have more than one wellchild visit during the course of the study, only the first visit was evaluated. In addition, if a family had more than one child in the 0 - to 24-month range, only information about the youngest child was used for the study.

\section{Procedure}

Before its initiation, the study was approved by the University of Minnesota Institutional Review Board. In addition, the interview was piloted on 5 English- and 5 Hmong-speaking parents. Results of this pilot study were used to refine the survey and other study procedures.

A list of children due for a well-child visit was obtained from the clinic's business office. The list included children who had kept or "no-showed" for a well-child visit and those who were due for a visit but did not have a visit scheduled. Parents from each of these 3 groups were invited to participate in the study initially by a letter, and they were given an opportunity to decline participation in the study by leaving a voice message on a designated telephone line.

Three bilingual (English- and Hmong-speaking) research assistants and the fourth author contacted prospective subjects by telephone to determine their eligibility and willingness to participate. (Although this clinic serves other non-English-speaking patients-eg, Latino and Somali-these were not included in the study because they comprise a small minority of the clinic population, and interpreters were not readily available.) If more than 2 months had elapsed since the child's most recently kept or missed well-child visit, the case was labeled "late," and a call was not made. When telephone contact was made with a household, the interviewer asked to speak with the parent responsible for scheduling the child's doctor visits. The responsible parent was briefly informed about the study; if that parent was interested in participating, he or she was read the consent procedure and asked about his or her willingness to participate. Willing parents were then administered a telephone survey that required approximately 10 to 15 minutes to complete.

\section{Surveys}

The telephone survey included the following information. 


\section{Demographic Characteristics}

Parent's and child's age, number of children (including number of children under 5 years of age), gender, ethnicity, marital status, education, employment status, and insurance type (private vs medical assistance; if medical assistance, UCare vs non-UCare).

\section{Well-Child Visit Characteristics}

Whether most recent well-child visit was missed or kept, reason for missing visit (choices included transportation problems, forgot, child's or other family member's illness, too busy, no care for other children, visit not needed, visit against beliefs or culture), whether appointments were recorded on a calendar, whether ride to visit was provided by insurance, difficulty of obtaining transportation for well-child visit $(1=$ very difficult, $5=$ not at all difficult), parent's perceived importance of wellchild visit, parent's perceptions about why visit is important (choices include receiving immunizations, measurement of growth, full physical examination, assessment of development, counseling on safety, parenting, nutrition, etc), whether visit reminder is helpful and, if so, the type of reminder preferred.

\section{Health Characteristics of Parents and Children}

Two-question depression screen described by Whooley and Simon ${ }^{12}$ (bothered by feeling down, depressed, or hopeless over the past month; bothered by having little interest or pleasure in doing things), stress level over past month $(1=$ not at all stressed, 3 = often stressed, $5=$ always stressed), cause of stress (choices include having too much to do, employment, illness, financial, conflict with partner or extended family, lack of help from partner), and number of child's illness days over past month. To identify and appropriately manage parents with suicidal ideation, parents who gave affirmative responses to either of the depression screening questions were asked if, over the past month, they had ever felt so depressed that they had thought of harming themselves or someone else.

\section{Data Analysis}

Descriptive analyses were performed on demographic, well-child visit, and health characteristics. Logistic regression analysis was performed to identify factors that predicted noncompliance with well-child visits. For this analysis, the dependent variable was failure to keep the most recent wellchild visit, and independent variables included: child's age, parent's age and gender, ethnicity, private versus public assistance-sponsored health insurance, UCare versus non-UCare insurance (to assess the importance of insurance-provided transportation), transportation difficulty, insurance-provided transportation to visit, education, employment status, hours employed per week, number of children, number of children less than 5 years of age, marital status, stress level, depressive symptoms, number of child's illness days over the past month and perceived importance of well-child visit.

\section{Results \\ Sample}

During the period of the study, 608 children aged 0 to 24 months who were enrolled at Bethesda Clinic either had or should have had a well-child visit. Telephone contact was made with 269 parents of these children (one parent per household); 69 of these parents were not eligible to participate. Of the 200 contacted parents who were eligible, 146 (73\%) agreed to participate in the study (see Figure 1 for a breakdown of potential subjects). The study population therefore consisted of 146 parents who were primarily young, married, low-income women, of Southeast Asian, African American, and white descent. A more detailed description of the population is provided in Table 1 .

\section{Well-Child Visit Characteristics: Compliance and Parent's Attitude}

Characteristics of well-child visits and parents' attitudes toward these visits are shown in Table 2. Most of the scheduled well-child visits were kept. According to parents' reports, 14\% of expected visits were missed: they were either not scheduled or scheduled but not kept. The most common reason for missing the appointment was that parents forgot about the visit, even though $82 \%$ said they recorded appointments on the calendar. Most parents said they would like a visit reminder, and a majority preferred telephone reminders to letters. All the subjects agreed that well-child visits were important for various reasons; the most common reason was immunizations. Rides were provided by UCare insurance for 37\% (20 of 54) of UCare members. 


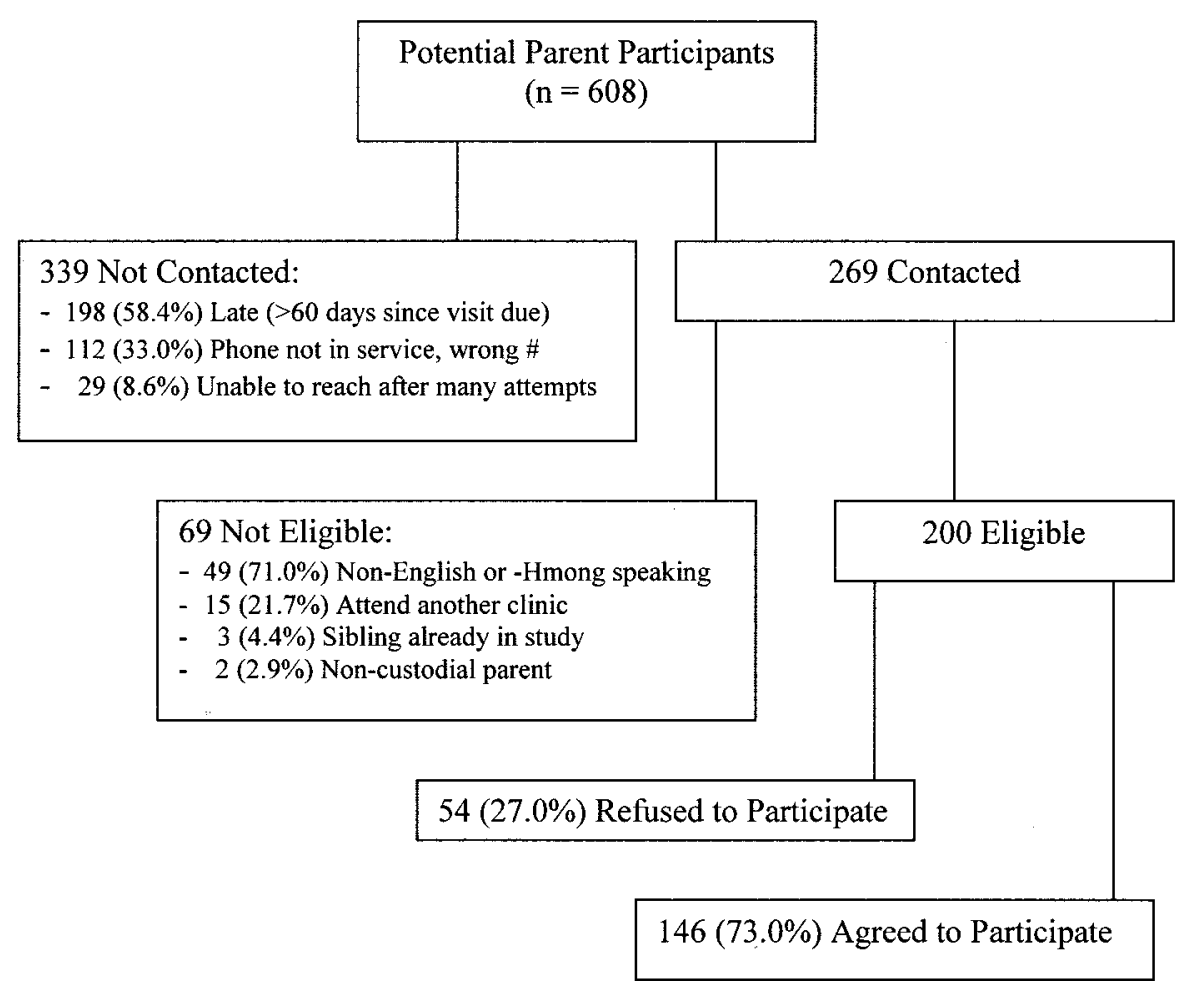

Figure 1. Sample of participants and nonparticipants.

Table 1. Characteristics of Participants $(n=146)$

\begin{tabular}{|c|c|c|c|c|}
\hline & $\mathrm{N}$ & $\%$ & Mean & S.D. \\
\hline $\begin{array}{c}\text { Gender } \\
\text { Female } \\
\text { Male }\end{array}$ & $\begin{array}{r}131 \\
15\end{array}$ & $\begin{array}{l}89.7 \\
10.3\end{array}$ & & \\
\hline $\begin{array}{l}\text { Ethnicity } \\
\text { Southeast Asian } \\
\text { African American } \\
\text { White } \\
\text { Latin American } \\
\text { Native American } \\
\text { Other }\end{array}$ & $\begin{array}{r}94 \\
21 \\
20 \\
4 \\
4 \\
3\end{array}$ & $\begin{array}{r}64.8 \\
14.5 \\
13.8 \\
2.8 \\
2.8 \\
2.1\end{array}$ & & \\
\hline $\begin{array}{l}\text { Marital Status } \\
\text { Married } \\
\text { Single, not living with partner } \\
\text { Single, living with partner } \\
\text { Separated }\end{array}$ & $\begin{array}{r}90 \\
32 \\
24 \\
1\end{array}$ & $\begin{array}{r}61.2 \\
21.8 \\
16.3 \\
0.7\end{array}$ & & \\
\hline $\begin{array}{l}\text { Education } \\
<12 \text { th grade } \\
\text { High School diploma } \\
\text { Post-high school }\end{array}$ & $\begin{array}{l}70 \\
40 \\
35\end{array}$ & $\begin{array}{l}48.3 \\
27.6 \\
24.1\end{array}$ & & \\
\hline Employed & 73 & 50.3 & & \\
\hline Age in years & & & 25.9 & 7.2 \\
\hline Child's age in months & & & 8.9 & 5.4 \\
\hline Number of children & & & 3.0 & 2.2 \\
\hline Number of children $<5$ years & & & 1.7 & 0.8 \\
\hline $\begin{array}{l}\text { Medical Insurance } \\
\text { Public Assistance } \\
\text { Private or other } \\
\text { None }\end{array}$ & $\begin{array}{c}99^{*} \\
45 \\
3\end{array}$ & $\begin{array}{r}67.3 \\
30.6 \\
2.0\end{array}$ & & \\
\hline
\end{tabular}

* 54 of these patients were on UCare, a form of Public Assistance.

\section{Parents' Mental Health}

Twenty percent of participants (29 of 146), including 27 mothers and 2 fathers, had positive depression screens. Of these 29 parents, 2 had thought of harming themselves in the recent past. Although neither person felt this way at the time of the survey and neither harmed themselves or someone else during the course of the study, both were urged to see their physician very soon. Twenty percent of subjects also indicated that they were "often to always" stressed (Table 3). The most commonly reported causes of stress were having too much to do, financial concerns, and employment issues.

\section{Children's Illness Days}

Parents reported that their child was ill an average of 3.6 (S.D., 5.6) days in the past month.

\section{Predictors of Well-Child Visit Noncompliance}

Whether a well-child visit was kept was significantly related to several demographic and health variables, as noted in Table 4. Not keeping the most recent well-child visit was associated with being an older (vs younger) parent, working at a job, having private insurance (vs public assistance), having depressive symptoms, and having transpor- 


\begin{tabular}{|c|c|c|c|c|}
\hline & $\mathrm{N}$ & $\%$ & Mean & S.D. \\
\hline \multicolumn{5}{|l|}{ Visit Compliance and Related Factors } \\
\hline \multicolumn{5}{|l|}{ Visit compliance } \\
\hline Well-child visit made & 126 & 86.3 & & \\
\hline Appointment not scheduled & 14 & 9.6 & & \\
\hline Appointment scheduled, but not kept & 6 & 4.1 & & \\
\hline \multicolumn{5}{|l|}{ Reasons for missing visit } \\
\hline Forgot & 18 & $90.0^{*}$ & & \\
\hline Too busy & 7 & $35.0^{*}$ & & \\
\hline Transportation problems & 5 & $25.0^{*}$ & & \\
\hline No care for other children & 3 & $15.0^{*}$ & & \\
\hline Child ill & 2 & $10.0^{*}$ & & \\
\hline Transportation difficulty & & & $4.3^{\dagger}$ & 1.2 \\
\hline Record appointments on calendar & 110 & 82.1 & & \\
\hline Ride provided for visit by UCare insurance & 30 & 24.0 & & \\
\hline \multicolumn{5}{|c|}{ Parents' Attitudes toward Well-Child Visits and Visit Reminders } \\
\hline Parent thought well-child visit was important & 146 & 100.0 & & \\
\hline \multicolumn{5}{|l|}{ Why well-child visit is important } \\
\hline Immunizations & 102 & 69.4 & & \\
\hline Child development & 81 & 55.1 & & \\
\hline Growth measurements & 47 & 32.0 & & \\
\hline Full exam & 42 & 28.6 & & \\
\hline Counseling on parenting, safety & 20 & 13.6 & & \\
\hline Parents thought appointment reminder was helpful & 103 & 77.4 & & \\
\hline \multicolumn{5}{|l|}{ Type of appointment reminder preferred } \\
\hline Phone call & 71 & 68.3 & & \\
\hline Letter & 24 & 23.1 & & \\
\hline Either & 9 & 8.7 & & \\
\hline
\end{tabular}

* Percentage given as proportion of missed visits $(n=20)$.

${ }^{\dagger}$ Responses given on 1 to 5 scale, where 1 = very difficult, $3=$ somewhat difficult, and $5=$ not at all difficult.

tation difficulties. Together, these factors explained $42 \%$ of the variance in whether a visit was kept or missed.

\section{Discussion}

Well-child visits are important to a child's health, as unanimously affirmed by the parents who were surveyed here and as demonstrated by previous research showing that missed well-child visits are associated with more frequent hospitalizations ${ }^{2}$ and emergency department visits. ${ }^{13}$ Despite their recognition of the importance of well-child visits, $14 \%$ of surveyed parents acknowledged that they had missed a recent well-child visit; the most common reason was that they simply forgot. More than three fourths of parents believed that visit remind-

Table 3. Parents' Mental Health $(n=146)$

\begin{tabular}{|c|c|c|c|c|}
\hline Parent & $\mathrm{N}$ & $\%$ & Mean & S.D. \\
\hline Bothered by feeling down, depressed, or hopeless over past month & 27 & 18.4 & & \\
\hline Bothered by having little interest or pleasure in doing things & 17 & 11.6 & & \\
\hline Positive depression screen ('yes' to either of above 2 items) & 29 & 19.7 & & \\
\hline Cries often for known or unknown reasons & 18 & 12.2 & & \\
\hline Stress level over past month & & & $1.9^{*}$ & 0.9 \\
\hline Often stressed to always stressed & 29 & 19.9 & & \\
\hline $\begin{array}{l}\text { Causes of stress } \\
\text { Too much to do } \\
\text { Financial concerns } \\
\text { Employment } \\
\text { Illness } \\
\text { Lack of help from spouse/partner } \\
\text { Conflict with partner } \\
\text { Conflict with extended family }\end{array}$ & $\begin{array}{r}24 \\
14 \\
6 \\
3 \\
2 \\
1 \\
1\end{array}$ & $\begin{array}{c}82.8^{+} \\
48.3^{+} \\
20.7^{+} \\
10.3^{+} \\
6.9^{+} \\
3.4^{+} \\
3.4^{+}\end{array}$ & & \\
\hline
\end{tabular}

* Responses given on a 1 to 5 scale, where $1=$ not at all stressed, $3=$ often stressed, and $5=$ always stressed.

${ }^{\dagger}$ Percentage given as proportion of people who were often to always stressed $(n=29)$. 
Table 4. Predictors of Well-Child Visit Noncompliance

\begin{tabular}{lccc}
\hline Independent Variable & Standardized $\beta$ & $P$ Value & Odds Ratio (C.I.) \\
\hline Working at a job & 2.33 & .002 & $10.0(2.23,47.47)$ \\
Insurance: private vs. public & 1.84 & .022 & $6.25(1.26,31.50)$ \\
Depressive symptoms & 1.50 & .039 & $4.55(1.05,19.11)$ \\
Transportation availability & -0.69 & .005 & $0.50(1.22,3.25)$ \\
Age & 0.12 & .006 & $1.12(1.03,1.23)$ \\
Nagelkerke's Pseudo R square $=0.42$ & & & \\
\hline
\end{tabular}

ers were helpful—a useful finding for this setting in which reminders are not routinely given. The value of appointment reminder systems is also supported by prior research, which shows that such systems increase the frequency of follow-up visits. ${ }^{9,14}$

Several important factors were associated with missed well-child visits: parents' depressive symptoms, transportation difficulties, being older and employed, and having private (vs public) health insurance. The relationship between missed wellchild visits and parents' depressive symptoms (seen in one fifth of our parents) is particularly noteworthy. Previous research has shown that parental depression can impact children in several ways. For example, parents' depressive symptoms have been associated with their offspring's diminished men$\mathrm{tal}^{15,16}$ and physical health, ${ }^{17}$ and functioning. ${ }^{18}$ More specific to this study, research conducted in a British child psychiatry clinic showed that parental depression was associated with a child's default from psychiatric treatment through visit noncompliance. $^{8}$ Our findings expand this literature, in that they show an association between parental depressive symptoms and noncompliance with well-child visits in a primary care population. Importantly, these findings suggest that a missed well-child visit may serve as a marker for more serious parental or family distress. If this holds true in other settings, it may be prudent for health care providers to develop mechanisms to monitor those at risk with follow-up telephone calls, for example.

Transportation difficulty was also significantly related to missed well-child visits. Given this finding, one might expect that the provision of free transportation would encourage visit compliance. Indeed, Melnikow et $\mathrm{al}^{11}$ found that when taxi vouchers were given to low-income expectant mothers, attendance at the first prenatal visit increased by $22 \%$. However, in the current study, having an insurance-sponsored transportation benefit (available to all UCare members) was not asso- ciated with visit compliance. It is possible that not all UCare participants were aware of their transportation benefit or knew how to use it. Even if they were aware, some members may not have taken the initiative to prearrange the ride at least 24 hours before the scheduled visit, as required by this insurer. Thus, it is possible that, apart from the transportation benefit itself, the ease of engaging the benefit may contribute to visit attendance. Future studies should investigate methods for maximizing patients' access to transportation, as well as the health outcomes of such programs.

Visit noncompliance was also associated with parents' employment status, age, and health insurance. It makes sense that employed parents would have less flexibility to attend well-child visits. However, given the importance of these visits, employers should be encouraged to allow parents to take time for these routine visits. The association of missed visits with age and private insurance is more difficult to explain. It is possible that older parents have more complex lives, making it more difficult to attend well-child visits. In addition, copayments, often required by private insurance, could be a deterrent to keeping well-child visits.

This study has some limitations. First, our results may not be generalizable because we studied a modest sample of parents from a single clinic. This sample was indeed unique, as evidenced by several of its characteristics: only $14 \%$ were white $(65 \%$ were Southeast Asian and 15\% African American), $67 \%$ were insured through public assistance, $48 \%$ did not have a high school diploma, and the children had relatively high rates of illness (average of 3.6 illness days/month). Many prospective subjects could not be reached, either because they had moved or because their phones had been disconnected. Other researchers have found that persons without telephones are more difficult to reach and tend to have a relatively lower socioeconomic status. ${ }^{19}$ Although these difficulties in contacting po- 
tential subjects negatively impact recruitment, they should not be viewed as deterrents to studying populations that might have greater health risks. Also adversely affecting recruitment were the delays in contacting potential subjects (the "late," not contacted persons represented in Figure 1). These contact delays were caused by the limited time availability of our research assistants, who also worked as full-time medical assistants and Hmong interpreters at Bethesda Clinic (we were unable to recruit bilingual research assistants from the community). Another limitation of the study is our use of parents' subjective recall, which, for example, might produce a downward bias in number of missed visits. Finally, we treated noncompliance as a dichotomous variable (missed versus kept visits) in our logistic regression analysis; our findings may have been more accurate if we had treated visit noncompliance as a continuous variable, as proposed by Dubinsky. ${ }^{7}$

This study also had several strengths, however. It was conducted in a family practice setting, which is likely to be more representative of the general population than a specialized setting (eg, child psychiatry clinic) would be. Like other family practice clinics, this clinic often serves both the children and parents in a given family, making it more natural to include survey questions that relate to both children's and parents' health. Our sample was diverse, representing Asian, African American, and white groups, and we included both Hmong- and English-speaking subjects. It is noteworthy that we included health variables in our regression equation on missed visits and found a link between parents' depressive symptoms and children's missed visits.

In conclusion, parents in this low-income, ethnically diverse population were in unanimous agreement that well-child visits are important. However, some well-child visits were missed, mostly because parents forgot to schedule or attend them. Missed visits were associated with parents' depressive symptoms, transportation difficulties, private insurance, age, and working at a job. If confirmed by other studies, these findings could help suggest ways to improve well-child visit compliance, for example through transportation programs and employers' provision of time away for well-child visits. Our results also suggest that missed well-child visits could serve as a marker for at-risk parents and families.

\section{References}

1. Nevin JE, Witt DK. Well child and preventive care. Prim Care 2002;29:543-55.

2. Hakim RB, Bye BV. Effectiveness of compliance with pediatric preventive care guidelines among medicaid beneficiaries. Pediatrics 2001;108:90-7.

3. Smith CM, Yawn BP. Factors associated with appointment keeping in a family residency clinic. J Fam Pract 1994;38:25-9.

4. Dockerty JD. Outpatient clinic nonarrivals and cancellations. NZ Med J 1992;105:147-9.

5. Weingarten N, Meyer DL, Schneid JA. Failed appointments in residency practices: who misses them and what providers are most affected? J Am Board Fam Pract 1997;10:407-11.

6. Irwin CE Jr, Millstein SG, Ellen JM. Appointmentkeeping behavior in adolescents: factors associated with follow-up appointment-keeping. Pediatrics 1993;92:20-3.

7. Dubinsky M. Predictors of appointment noncompliance in community mental health patients. Community Ment Health J 1986;22:142-6.

8. Dover SJ, Leahy A, Foreman D. Parental psychiatric disorder: clinical prevalence and effects on default from treatment. Child Care Health Dev 1994;20: 137-43.

9. Casey R, Rosen B, Glowasky A, Ludwig S. An intervention to improve follow-up of patients with otitis media. Clin Pediatr (Phila) 1985;24:149-52.

10. Eisert S, Gabow P. Effect of child health insurance plan enrollment on the utilization of health care services by children using a public safety net system. Pediatrics 2002;110:940-5.

11. Melnikow J, Paliescheskey M, Stewart GK. Effect of a transportation incentive on compliance with the first prenatal appointment: a randomized trial. Obstet Gynecol 1997;89:1023-7.

12. Whooley MA, Simon GE. Managing depression in medical outpatients. N Engl J Med 2000;343: 1942-50.

13. Hakim RB, Ronsaville DS. Effect of compliance with health supervision guidelines among US infants on emergency department visits. Arch Pediatr Adolesc Med 2002;156:1015-20.

14. Knishkowy B, Palti H, Schein M, Yaphe J, Edman R, Baras M. Adolescent preventive health visits: a comparison of two invitation protocols. J Am Board Fam Pract 2000;13:11-6.

15. Billings AG, Moos RH. Comparisons of children of depressed and nondepressed parents: a social-environmental perspective. J Abnorm Child Psychol 1983;11:463-85.

16. Warner V, Weissman MM, Fendrich M, Wickramaratne $\mathrm{P}$, Moreau D. The course of major depression in the offspring of depressed parents: incidence, recurrence, and recovery. Arch Gen Psychiatry 1992; 49:795-801. 
17. Kramer RA, Warner V, Olfson M, Ebanks CM, Chaput F, Weissman MM. General medical problems among the offspring of depressed parents: a 10-year follow-up. J Am Acad Child Adolesc Psychiatry 1998;37:602-11.

18. Billings AG, Moos RH. Children of parents with unipolar depression: a controlled 1-year follow up. J Abnorm Child Psychol 1985;14:149-66.

19. Hardy RE, Ahmed NU, Hargreaves MK, et al. Difficulty in reaching low-income women for screening mammography. J Health Care Poor Underserved 2000;11:45-57. 